\title{
Refinement of Primary Silicon Crystals by Novel Al-ZnS Master Alloy in Solidification of Hypereutectic Al-Si Alloys
}

\author{
Kawther Al-Helal, Ian Stone and Zhongyun Fan \\ The EPSRC Centre - LiME, BCAST, Brunel University,Uxbridge, Middlesex, UB8 3PH, UK
}

Keywords: Hypereutectic Al-Si alloys, refinement, primary silicon, master alloy

\begin{abstract}
A novel Al-ZnS master alloy was developed by in situ reaction of $\mathrm{Zn}$ and $\mathrm{Na}_{2} \mathrm{~S}$ in the $\mathrm{Al}$ melt. The results from this study left little doubt that this novel Al-ZnS master alloy was a promising refiner in solidification of hypereutectic Al-Si alloys. It refined the primary silicon to the same extent as that achieved by adding $\mathrm{P}$ via $\mathrm{Cu}-\mathrm{P}$ following the same refinement mechanism. The SEM work confirmed that there were many pre-formed $\mathrm{ZnS}$ particles contained in the master alloy. The optical metallography showed that the morphologies of the primary silicon crystals in the solidified $\mathrm{Al}-22 \mathrm{Si}$ alloy were drastically changed from irregular coarse morphology to fine regular particles. The primary silicon crystal was refined from $74 \mu \mathrm{m}$ to $26,22,24 \mu \mathrm{m}$ by adding 0.05 , $0.1,0.15 \mathrm{wt} \% \mathrm{ZnS}$ respectively with holding time of $20 \mathrm{~min}$, whereas the average particle size of the primary silicon refined by $200 \mathrm{ppm} \mathrm{P}$ reduced to $20 \mu \mathrm{m}$. With the increase of the holding time up to $1.5 \mathrm{hr}$, the primary silicon size will increase up to $33 \mu \mathrm{m}$ in adding $0.1 \mathrm{wt} \% \mathrm{ZnS}$.
\end{abstract}

Key words Hypereutectic Al-Si alloys, refinement, primary silicon, master alloy.

\section{Introduction}

Hypereutectic Al-Si alloys are of increasing interest for applications that require a combination of light weight and high wear resistance, such as pistons, liner-less engine blocks and pumps. The wear resistance of this class of alloys is due to the presence of hard primary Si particles formed during casting [1, 2]. For hypereutectic Al-Si alloys, the final properties in the cast component are controlled by the size and distribution of the primary silicon phase in addition to the degree of modification of the eutectic silicon matrix [3]. To maximise machine tool life while taking advantage of the high wear resistance of hypereutectic Al-Si alloys, the primary Si crystals formed during solidification should be as fine and uniformly dispersed as possible. The current commercial practice is to add phosphorous in the form $\mathrm{Cu}-\mathrm{P}, \mathrm{Al}-\mathrm{Cu}-\mathrm{P}$ and $\mathrm{Al}-\mathrm{Fe}-\mathrm{P}$ master alloys, such that primary $\mathrm{Si}$ nucleates heterogeneously on AlP particles. The crystal structure and lattice parameter of AlP are close to that of silicon with the minimal mismatch between them, less than $1 \%$ [4].

Refining agents like $\mathrm{Ga}, \mathrm{Ge}, \mathrm{Se}, \mathrm{Be}, \mathrm{Te}, \mathrm{Li}, \mathrm{Cd}, \mathrm{Zn}, \mathrm{Mn}, \mathrm{V}, \mathrm{Cb}$, $\mathrm{Bi}, \mathrm{Mo}, \mathrm{Hf}$ and $\mathrm{S}$ either individually or in combination have also been studied. These agents along with $\mathrm{Na}$ would give simultaneous silicon refinement and eutectic modification [5]. A significant refinement of primary silicon in 390 alloy has been reported with the use of Germanium, Gallium, Selenium, Tellurium, Lithium, Cadmium, and Lithium Chloride [6].
Due to the structural similarity of $\mathrm{ZnS}$ in its zincblende form, and its similar lattice parameter to those of Si and AlP, its use as an inoculant to refine the primary $\mathrm{Si}$ in solidification of hypereutectic $\mathrm{Al}-\mathrm{Si}$ alloys was examined in this study. $\mathrm{ZnS}$ occurs in two common polytypes, zincblende (also called sphalerite: cubic with lattice parameter ao $=5.41 \AA$ ) and wurtzite (hexagonal with lattice parameters $\mathrm{a}_{\mathrm{o}}=3.2495 \AA \mathrm{c}_{\mathrm{o}}=5.2069 \AA$ ) . ZnS crystallizes with the cubic zincblende structure below $1020{ }^{\circ} \mathrm{C}$ and with the hexagonal wurtzite structure above this phase transition temperature [7]. The refinement efficiency of $\mathrm{ZnS}$ in solidification of the hypereutectic Al-Si alloys has been investigated. Experiments were conducted to refine the primary silicon particles in Al-Si alloy by adding the new Al-ZnS master alloy.

\section{Experimental procedures}

The initial batches of Al-Si alloys were prepared in an electric resistance furnace by melting and diluting an Al-50Si master alloy with commercial purity aluminium LM0 at $1100{ }^{\circ} \mathrm{C}$ for $3 \mathrm{~h}$ in a clay crucible. The compositions of raw materials are listed in Table 1. For homogeneity, the molten alloy was manually stirred for a few seconds and then cast.

Table 1 Aluminium alloys composition wt $\%$

\begin{tabular}{ccccccccccccc}
\hline Alloy & $\mathrm{Cu}$ & $\mathrm{Mg}$ & $\mathrm{Si}$ & $\mathrm{Fe}$ & $\mathrm{Mn}$ & $\mathrm{Ni}$ & $\mathrm{Zn}$ & $\mathrm{Pb}$ & $\mathrm{Sn}$ & $\mathrm{Ti}$ & $\mathrm{Cr}$ & $\mathrm{Al}$ \\
\hline LM0 & 0.03 & 0.03 & 0.30 & 0.40 & 0.03 & 0.03 & 0.07 & 0.03 & 0.03 & - & - & Bal. \\
Al-50Si & 0.08 & 0.28 & 51.0 & 0.32 & 0.02 & 0.01 & 0.02 & 0.02 & 0.01 & 0.09 & 0.03 & Bal. \\
\hline
\end{tabular}

One synthesis method for zincblende $\mathrm{ZnS}$ nanoparticles is by chemical reaction using $\mathrm{Zn}$ and $\mathrm{Na}_{2} \mathrm{~S}$ [8]. Experiments were carried on to prepare the Al-ZnS master alloy by adding the stoichiometric amount of $\mathrm{Zn}$ metal followed by adding $50 \%$ excess of $\mathrm{Na}_{2} \mathrm{~S}$ powder to high purity aluminium melt with gentle mixing at $800{ }^{\circ} \mathrm{C}$ for $20 \mathrm{~min}$. The produced master alloy cast in cylindrical mould pre-heated to $200{ }^{\circ} \mathrm{C}$, and cooling in air at a cooling rate of approximately $16 \mathrm{~K} / \mathrm{s}$.

Another set of experiments was conducted to refine Al-22Si alloy by adding different amount of the Al-ZnS master alloy for different holding time. In order to compare with $\mathrm{P}$ refinement, the $\mathrm{Al}-\mathrm{Si}$ alloy was remelted to $800{ }^{\circ} \mathrm{C}$ and then $\mathrm{P}$ was added in the form of CuP shot (Supplied by Aura Metals Ltd). The molten alloy was manually stirred for a few seconds and sample was taken after $20 \mathrm{~min}$. Samples for all above experiments were taken by a Boron Nitride coated steel mould $(35 \mathrm{~mm}$ in diameter and $40 \mathrm{~mm}$ in height with long handle) preheated at $200{ }^{\circ} \mathrm{C}$ which was then water cooled at approximately $15 \mathrm{~K} / \mathrm{s}$. Longitudinal sections of resulting samples were prepared by the standard technique of grinding with $\mathrm{SiC}$ abrasive papers and polishing with $1 \mu \mathrm{m}$ 
diamond suspension followed by silica suspension. The chemical composition of all alloys was analysed using a "Worldwide Analysis System (WAS) AG, Foundry master". Microstructure characterization was accomplished using an optical microscope (Carl Zeiss Axioskop 2 MAT) equipped with image analysis software. The scanning electron microscopy (SEM) examination was carried out using a Zeiss Supera 35 FEG and JEOL 840 microscopes. The microscope equipped with an energy dispersive spectroscopy (EDS) facility, operated at an accelerating voltage of 5-20 KV.

\section{Results and discussion}

\section{Preparation of Al-ZnS Master Alloy}

$\mathrm{Al}-\mathrm{ZnS}$ master alloy was prepared by adding the stoichiometric amount of $\mathrm{Zn}$ followed by adding excess amount of $\mathrm{Na}_{2} \mathrm{~S}$ to high purity aluminium at $800{ }^{\circ} \mathrm{C}$. The SEM micrographs and EDX analysis confirm the formation of $\mathrm{ZnS}$ particle in the master alloy as shown in Figure 1. The higher Al content can be attributed to the small size of the $\mathrm{ZnS}$ particle and large beam size used for EDX measurement. It is clear that $\mathrm{ZnS}$ particle can be precipitated in the melt and its formation is according to the following chemical equation;

$\mathrm{Na}_{2} \mathrm{~S}+\mathrm{Zn}^{+} \longrightarrow \mathrm{ZnS}+2 \mathrm{Na}^{+}$

The same principle is used to remove $\mathrm{Zn}$ from the wastewater or etching solution as $\mathrm{ZnS}$ by adding $\mathrm{Na}_{2} \mathrm{~S}$ [9]. $\mathrm{ZnS}$ crystallizes with the cubic zincblende structure below $1020{ }^{\circ} \mathrm{C}$ and with the hexagonal wurtzite structure above this phase transition temperature [10]. Since, the master alloy prepared at $800{ }^{\circ} \mathrm{C}$ so the precipitated particles are zincblende $\mathrm{ZnS}$. From the chemical analysis of the master alloy and according to the chemical equation, the composition of the master alloy is $\mathrm{Al}-1.5 \mathrm{wt} \% \mathrm{ZnS}$. Further work is in progress to separate these $\mathrm{ZnS}$ particles for full characterisation and optimize the master alloy composition and results will be reported elsewhere.
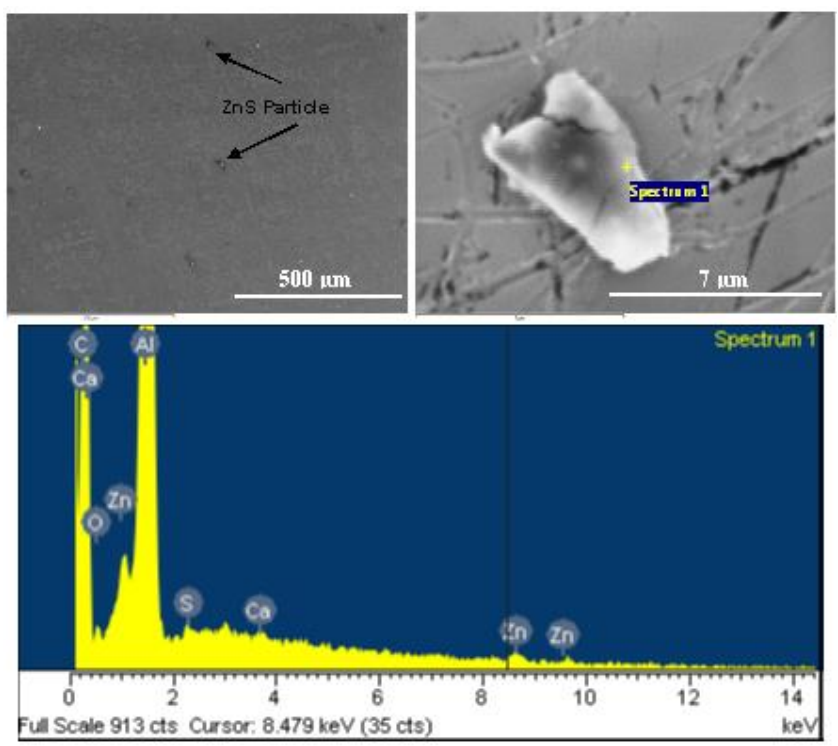

Figure 1 SEM micrographs and EDX analysis graphs showing the formation and structure of precipitated $\mathrm{ZnS}$ particles.

\section{Refinement of Primary Silicon by Al-ZnS Master Alloy}

Primary results encouraged us to use this master alloy to examine its refinement performance in solidification of the higher $\mathrm{Si}$ content of hypereutectic Al-Si alloys. The optical micrographs in Figure 2 show the refinement performance of $\mathrm{Al}-1.5 \mathrm{ZnS}$ master alloy in solidification of Al-22Si alloy. The untreated Al-22Si, Figure $2(\mathrm{a} \& \mathrm{~b})$ contained irregular coarse primary Si with average particle size of approximately $74 \mu \mathrm{m}$ and because of high $\mathrm{Ca}$ content in commercial purity alloy (> $200 \mathrm{ppm}$ ) the eutectic Si had a mostly fibrous morphology.
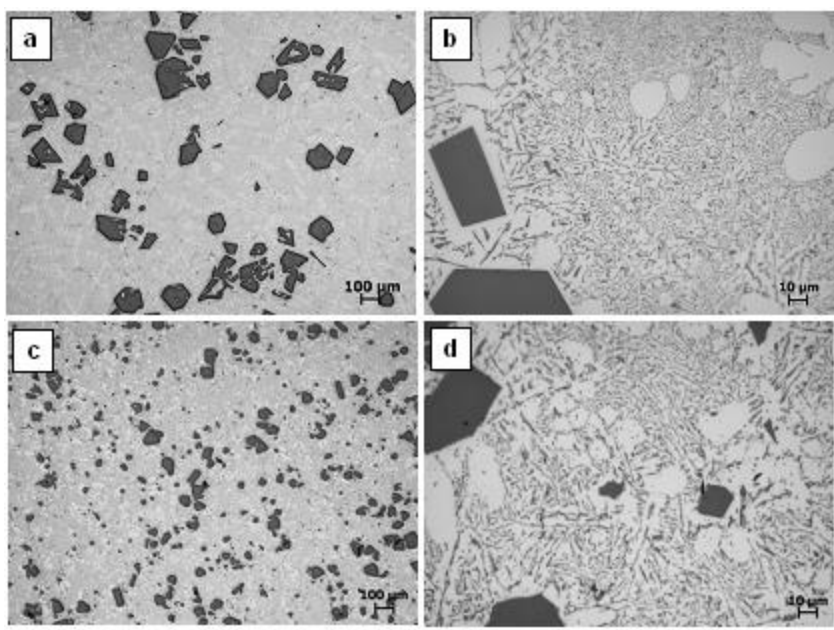

Figure 2 The optical micrographs of; (a, b) Al-22Si, (c, d) Al-22Si with the addition of $0.05 \mathrm{wt} \% \mathrm{ZnS}$ cast after $20 \mathrm{~min}$. (a, c) low magnification and $(b, d)$ high magnification.

Refinement with Al-1.5ZnS master alloy show that the particle size of primary silicon reduced to 26,22 and $26 \mu \mathrm{m}$ in adding $0.05,0.1$ and $0.16 \mathrm{wt} \%$ of $\mathrm{ZnS}$ respectively with $20 \mathrm{~min}$ holding time as shown in Figure 2 (c\&d) and 3. The morphologies of primary silicon crystals in solidification of Al-22Si alloy are drastically changed from irregular morphologies to regular morphologies with some lose in the modification of the eutectic $\mathrm{Si}$ matrix.
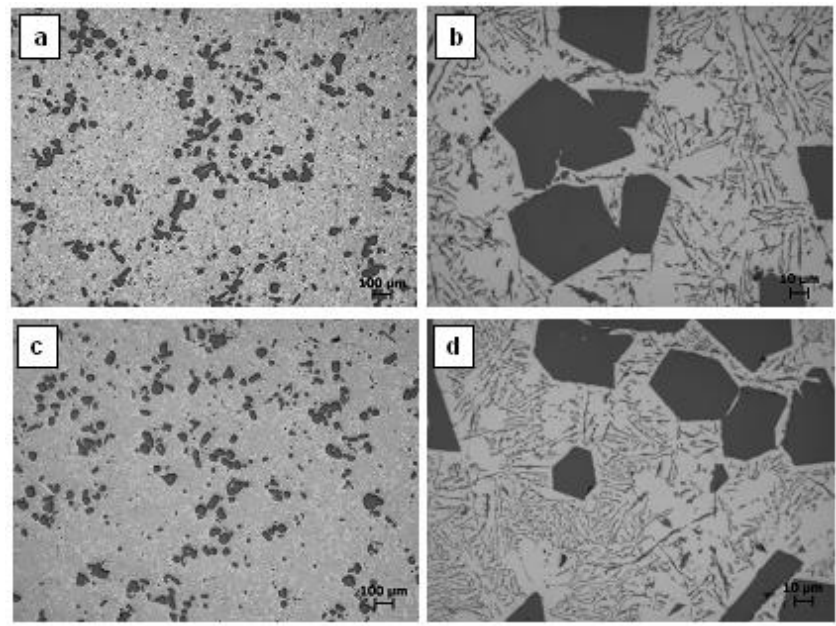

Figure 3 The optical micrographs of Al-22Si cast after $20 \mathrm{~min}$; (a, b) $\mathrm{Si}$ with the addition of $0.1 \% \mathrm{ZnS},(\mathrm{c}, \mathrm{d})$ with the addition of $0.16 \% \mathrm{ZnS}(\mathrm{a}, \mathrm{c})$ low magnification and $(\mathrm{b}, \mathrm{d})$ high magnification. 
It was clear that with the increase of $\mathrm{ZnS}$ content the average particle size of the primary silicon decrease with up to $0.1 \mathrm{wt} \%$ $\mathrm{ZnS}$. Above $0.1 \mathrm{wt} \% \mathrm{ZnS}$ the size of primary silicon increases again, this could be due to the agglomeration of $\mathrm{ZnS}$ particles in the melt. With the increase of the holding time up to $90 \mathrm{~min}$, the average particle size of primary silicon reduced from $74 \mu \mathrm{m}$ to 33 $\mu \mathrm{m}$ by adding $0.1 \mathrm{wt} \%$ of $\mathrm{ZnS}$ in solidification of $\mathrm{Al}-22 \mathrm{Si}$ as shown in Figure 4.

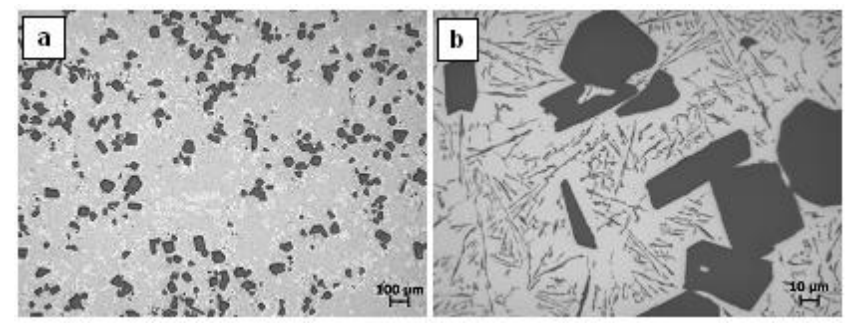

Figure 4 The optical micrographs of $\mathrm{Al}-22 \mathrm{Si}$ with the addition of $0.1 \% \mathrm{ZnS}$ cast after $1.5 \mathrm{hr}$. (a) low magnification and (b) high magnification.

This inefficiency in the refinement of primary Si at high holding time could be due to the agglomeration of $\mathrm{ZnS}$ particles which then produce larger size if compared with that produced in $20 \mathrm{~min}$ holding time. Also, the high holding time leads to continuous removal of the $\mathrm{Ca}$ by oxidation, and then the eutectic $\mathrm{Si}$ matrix loses its modification.

The chemical composition of Al-22Si alloy after adding the master alloy $(0.1 \% \mathrm{ZnS})$ analysed using a "Worldwide Analysis System (WAS) AG, Foundry master" showed that the Si composition reduced to around $20 \% \mathrm{Si}$ because of dilution. Hence, to compare with $\mathrm{P}$ refinement, an experiment was conducted by adding $200 \mathrm{ppm}$ of $\mathrm{P}$ to Al-20Si alloy. The average particle size of primary silicon was reduced to $20 \mu \mathrm{m}$, as shown in Figure 5 .

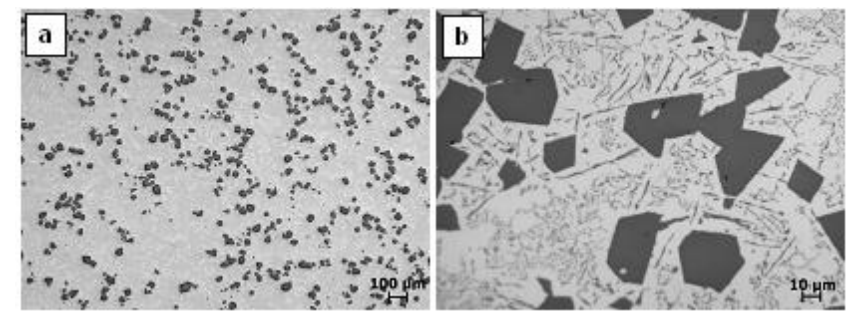

Figure 5 The optical micrographs of Al-20Si alloy with the addition of $200 \mathrm{ppm}$ P. (a) low magnification and (b) high magnification.

In using $\mathrm{P}$ for refinement of primary silicon in hypereutectic $\mathrm{Al}-\mathrm{Si}$ alloy, AIP particles will form in-situ which has a zincblende crystal structure with a lattice constant of $5.431 \AA$. These particles are suspended in the melt and act as potent sites for epitaxial nucleation of primary silicon [11].

It is very clear that the in-situ prepared zincblende $\mathrm{ZnS}$ have the same efficiency of $\mathrm{P}$ refinement of primary silicon and follow the same refinement mechanism.

\section{Summary}

The conclusions from the results of this study are:

1. According to the heterogeneous nucleation theory, $\mathrm{ZnS}$ particles act as potent substrate for nucleation of primary silicon. The lattice parameter of zincblende cube $\mathrm{ZnS}$ is $5.41 \AA$ which is similar to that of silicon with a lattice mismatch of less than $1 \%$. The primary Si nucleates and then grows by wrapping around the $\mathrm{ZnS}$ nucleant to develop as a compact particle.

2. The results from this study leave no doubt that the novel $\mathrm{Al}-\mathrm{ZnS}$ master alloy is a promising refiner in solidification of hypereutectic $\mathrm{Al}-\mathrm{Si}$ alloys. It has the same efficiency of $\mathrm{CuP}$ in the refinement of primary silicon and follows the same refinement mechanism. It seems that there is no interaction between $\mathrm{ZnS}$ and the $\mathrm{Ca}$ exists in the melt and hence there was no drop in modification of the eutectic Si in commercial purity Al-Si alloy.

\section{Acknowledgement}

The authors wish to thank Dr. Kumar Sundaram (Department of Materials, University of Oxford) for his helpful discussions on the contents of this article.

\section{References}

[1] Timpel M et al. 2012 J. Acta Materialia 60(9) p 3920-3928. [2] Hekmat-Ardakan A and Ajersch F 2011 J. Mater. Sci. 46 p 2370-2378.

[3] Jorstad J and Apelian D 2009 International Journal of Metalcasting, 3(3) p 13-36.

[4] Nogita K et al. 2004 Journal of Japanese Society of Microscopy 53(4) p 361-369.

[5] Mahanti R K et al. 1993 J. Mater. Trans. JIM 34(12) p $1207-$ 1211.

[6] Saha D et al. 2004 Inoculants for the Control of Primary Silicon Size and Distribution in Hypereutectic Alloys, in 8th International Conference on Semi solid Processing of Metals and Alloys: Limassol, Cyprus.

[7] Do Y R et al. 1992 J. Chem. Mater. 4(5) p 1014-1017.

[8] She Y et al. 2010 Trans. Nonferr. Metal Soc. China 20 p 211215.

[9] Lewis A E 2010 Hydrometallurgy 104 p 222-234.

[10] Do Y R et al. 1992 J. Chem. Mater. 4 p 1014-1017.

[11] Al-Helal K et al. 2012 Transactions of the Indian Institute of Metals 65(6) p 663-667. 